\title{
How far are the metropolitan areas in Brazil from achieving the sustainable development goals? An analysis based on SDG dashboards
}

\author{
Fernanda Silva Martinelli ${ }^{1}$ - André Lindner ${ }^{2}$
}

Received: 23 May 2020 / Accepted: 7 April 2021 / Published online: 23 April 2021

(c) The Author(s) 2021

\begin{abstract}
Cities comprise the major challenges for sustainable development and are key contributors to sustainability indicators in a country. However, research assessing sustainability performance often focuses on the national level, overlooking the role of urban areas. To evaluate the city performance toward a sustainable pathway, this paper proposes the sustainable development goals (SDGs) Dashboard for Brazilian Cities, with a comprehensive assessment of their specific challenges based on the SDG Index methodology (UNSDSN). The 19 country's most populous metropolitan areas (MAs) were considered, which comprises $41 \%$ of the population. From 17 SDGs, this paper evaluates 8 of the 12 SDGs defined with a social and environmental profile, covering data from 34 indicators. Results show that all MAs have a long way to achieve most of the analyzed SDGs, especially regarding inequalities (income and gender). Inequalities of performance are also observed among the country into a clear north-south distinction, where the GDP richest regions perform better toward the SDGs. However, cities with a good performance in education (SDG 4) are less unequal (SDG 10), indicating interrelations between SDGs. Despite the inequalities, MAs are doing relatively well in reducing poverty (SDG 1) and providing water and sanitation (SDG 6). The SDG Dashboards for Brazilian Cities can be used as a framework for action and help urban leaders address implementation challenges across cities.
\end{abstract}

Keywords Cities · Sustainable development · Monitoring · Indicators · Inequality · Education

Fernanda Silva Martinelli

fernanda.martinelli@uni-bonn.de

André Lindner

andre.lindner@tu-dresden.de

1 Center for Development Research, University of Bonn, Bonn, Germany

2 School of Civil and Environmental Engineering, Technische Universität Dresden, Dresden, Germany 


\section{Introduction}

In September 2015, world leaders from all UN Member States adopted the 2030 Agenda for Sustainable Development, in the form of the sustainable development goals (SDGs). The 17 SDGs seek to address economic, social and environmental issues in a sustainable manner underpinned by good governance (UN 2015). For the 15-year period the SDGs are covering, the world population is projected to increase by 1 billion people, and two-thirds of those will be living in cities (UN-DESA 2014). In terms of localizing the SDGs, previous research has shown that major challenges and opportunities are in the cities, with impacts in all the SDGs and not only the SDG 11 (Croese et al. 2020; ICSU 2017; Liu et al 2018). According to the Global Taskforce of Local and Regional Governments (GTLRG 2016), "localization relates both to how the SDGs can provide a framework for local development policy and to how local and regional governments can support the achievement of the SDGs through action from the bottom up." The localization is a key step during the "Decade of Action" (2020-2030) since 60\% of the SDGs are expected to be delivered at subnational level (UN 2019). Therefore, spatial clusters as cities concentrate benefits for development (e.g., agglomeration economies) for being the central locations for capital, labor and information (Fang and Yu 2017; Duranton and Puga 2004) as well as often face challenges with regards to extreme urban poverty, poor living conditions, lack of basic infrastructure and risks due to natural disasters and effects of climate variability.

Brazil is not an exception to this scenario. Although the country has improved its indicators for sustainable cities, it still has challenges to face, specifically on reducing inequalities and improving environmental conditions-challenges easily perceived across its cities and metropolitan areas (MAs) (Jahan 2016). However, there is almost never a silver bullet for such challenges, and more complex problems have arisen with population growth. This is certainly the case with the Brazilian MAs. Urban agglomeration turns neighboring cities into highly interdependent geographies that are connected socioeconomically with each other (Fang and Yu 2017; Gottmann 1957). Individual cities from MAs are forced to find solutions together, and two essential processes take place to overcome shared challenges: collaboration and peer-learning practices. In fact, when MA's cities work together to integrate initiatives (e.g., creating specialized departments for MA), common goals are reached faster, minimizing conflict of interest between municipal secretaries and local communities (RIDEsab 2017).

In Brazil, defining MAs is a measure to articulate and integrate the planning process among the cities. Since 1970, Brazil has experienced urban expansion from the central into peripheral cities, due to its rapid process of urbanization. Such spatial forms rapidly became a common form of human settlement in all its territory-following a trend echoed in urban areas around the world (Portnov and Schwartz 2009). In 2016, the country accounted for 38 MAs defined, of which 26 had more than one million inhabitants (IBGE 2017).

Defining MAs is also a strategy of getting the appropriate resources for facing beyond-borders challenges. The result is most likely to be suitable for all actors 

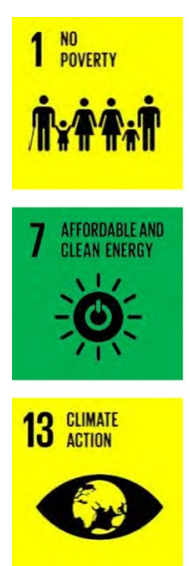
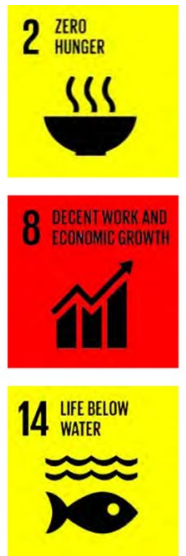
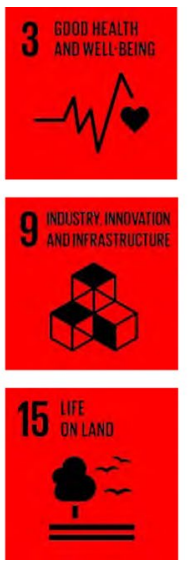
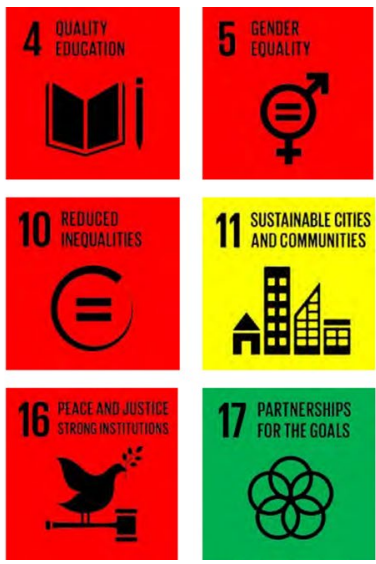
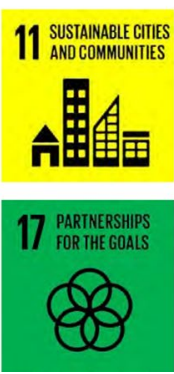
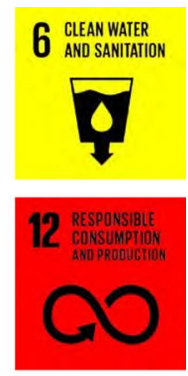

(6)

SUSTAINABLE GOALS

Fig. 1 Dashboard based on the average performance by SDG for Brazil, indicating whether the country has achieved or is on the path to achieve the goal (green), is in a "caution lane" (yellow), or is far from achievement (red). Source Sachs et al. (2016)

involved: the Federal Government saves financial resources, and the MAs through its more sizeable capacity have easier access to the means of financing in these sectors (Slack 2011). The result is also favorable for accomplishing the Agenda 2030: with the appropriate resource, integrated policies will support municipalities in operationalizing the SDGs, particularly those with regards to basic services. All SDGs have goals directly linked to the responsibilities of local and regional governments, and that is why "local and regional governments should be at the heart of Agenda 2030" (Prakash et al. 2017).

In summary, MAs have an extraordinary potential for transformational change when taking into account joint efforts toward achieving the SDGs. However, achieving the goals will depend mostly on the ability of local government to make them a reality (Aust and du Plessis 2018; Machado Filho 2016; Pahl-Wostl 2017). In fact, several indexes have been created recognizing the important role of urban areas in a national context, such as the Sustainable City Index (Arcadis 2018) and the City Biodiversity index (CBD 2019). However, for measuring SDGs performance, all indexes created a focus on countries or regions, but not in MAs. For Brazil, the SDG Index and Dashboard-Country Profile (Sachs et al. 2016) ranked the country 52nd among 149 countries (Fig. 1). This paper takes one step forward on the work of Sachs et al (2016) for countries and suggests an in-depth localized look at the performance of high-density subnational zones in Brazil, considering their key role for the SDGs.

Such an analysis requires a three-phased methodology to: (1) define the area of study, (2) create the SDG dashboards for each metropolitan area, and (3) compare their profile by providing a peer-learning tool. In general, urban challenges vary significantly from a place to another since not all municipalities are fit for the goals and possibly no one municipality performs outstandingly in every goal. Each city has its particular capacity to meet these goals and its own lessons to learn from the others (Croese et al. 2020). The outcome of this paper is to provide to municipal 


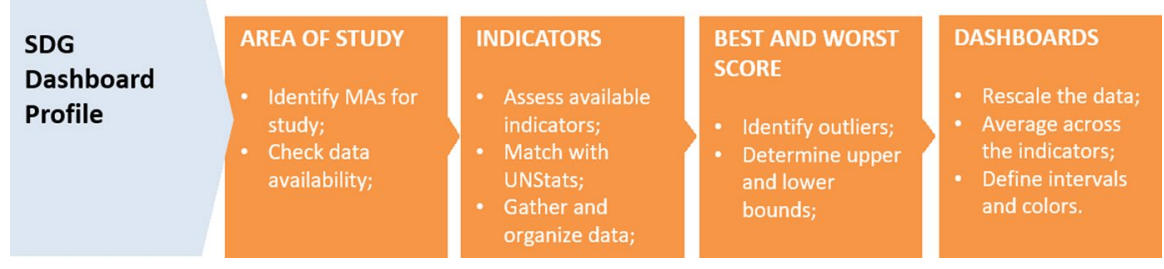

Fig. 2 Methodology steps for building the SDG Dashboard Profile for MAs. Source Author's elaboration

policy-makers a detailed profile of the strengths and weaknesses of MAs on the SDGs, to serve as a basis for the design and implementation of integrated local sustainable-oriented policies for their cities.

\section{Objectives}

In this study, we aimed to answer the question of how the most populous MAs in Brazil are performing relative to SDG targets, by comparing them through a dashboard profile. Its final goal is to serve as a management tool to enhance local policies and support the implementation of the SDGs in and by Brazilian municipalities located in MAs. Specifically, the objectives are:

1. To adapt the SDG Dashboard methodology from countries to MAs located in Brazil;

2. To provide an easy-to-understand and accessible dashboard profile that compares every metropolitan area with each SDG;

\section{Methodology}

The methodology for building the Metropolitan Area's Dashboards was based on the one developed initially for countries by the SDG Index and Dashboard-Country Profile Report (Sachs et al. 2016; Schmidt-Traub et al. 2017). Specifically, the methods selected for this paper involve four stages: (i) defining the area of study, (ii) selecting indicators, (iii) establishing best and worst scores, and finally, and (iv) creating dashboards (Fig. 2).

\section{Defining the area of study}

Metropolitan areas (MAs) were chosen as the focus of the SDG Dashboards. Although rural areas also present relevant challenges for SDG achievement, the metropolitan urban areas drive the change in both urban and rural spaces, leading up to a higher impact on the local-level implementation of the SDGs in Brazil (Doll 
2019). The MAs in this paper follows the definition used by the Brazilian Institute for Geography and Statistics (IBGE), and its population ranking.

According to IBGE, a set of clustering cities are only considered as a "metropolitan area" when they acquire a high level of integration among themselves, in economic, political and/or cultural aspects (IBGE 2017). When the urban clustering comprises municipalities from more than one State, the MA is called Integrated Region of Development (RIDE) (Federal Law 11.445/2007). For purposes of facilitating comprehension, in this study we name "MAs" both MAs and integrated regions of development.

In Brazil, the Federal States are the ones in charge of defining the MAs to manage the State's economic and social resources. According to the Federal Constitution of 1988, the MAs are defined as "groups of bordering municipalities to integrate the organization, planning and execution of public functions of common interest". In other words, MAs address essential tasks that require cooperation among municipalities, such as basic sanitation and collective transportation services.

Although MAs have similar urban challenges, they might comprise quite different historical and demographic urban realities. In Brazil, the former urbanization from Southeast, South and Northeast regions contrast with the Midwest and North regions, in which the urbanization occurred mostly in the twentieth century. While São Paulo and Rio de Janeiro have more than 21 million and 12 million inhabitants respectively, the MAs Macapá and Southwest Maranhense have only 463 and 334 thousand inhabitants, respectively (IBGE 2017). Demographic contrasts comprise different challenges. For minimizing differences in this study, the MAs selected were those with more than one million inhabitants who had available data from the Human Development Index (Atlas Brasil 2013) and could represent the five different regions of the country. Thus, the 19 most populous MAs were selected, which include 359 municipalities and almost 85 million inhabitants. We used the territorial configuration of August 1st, 2012, also considered by most of the indicators.

\section{Selection of indicators}

The indicators were selected considering the UN Statistical Commission (UNSTATS)'s official set of SDG monitoring indicators for the national level and the Brazilian Institute of Geography and Statistics (IBGE)'s SDG indicators, in charge of translating global indicators to national level. The UNSTAT adopted the indicator framework developed by the "Inter-Agency and Expert Group on SDGs indicators" (IAEG-SDGs) and where possible, the official indicators proposed by the IAEG-SDGs were used. However, other relevant municipal indicators better suited to monitoring at the urban level were identified in this study, replacing IAEGSDGs indicators not compatible with the local context in Brazil. It is worth noting that the IAEG framework is a "voluntary and country-led instrument" and one-third of the set of global indicators still lacks an agreed methodology (called Tier III indicators; IAEG 2016).

In addition to IAEG-SDGs indicators, data availability, data quality and coverage at the municipal level were also considered for selecting the MAs indicators. The 
indicators urban-related and having the most recent data were given preference, and they were classified in three different SDGs categories (Cutter et al. 2015): Social (SDGs 1-6, 10); Environmental (SDG 7, 12-15); and Economic and Political (SDGs $8,9,11,16,17)$. In this paper, we discuss eight SDGs from the two first categories (Social and Environmental SDGs), considering data availability for municipalities and the level of interactions between them.

The data were gathered mainly from federal statistical sources such as the Brazilian Institute of Geography and Statistics (IBGE) and the Department of Informatics of the Unified Health System (DATASUS). Data from Ministries of Cities, of Education, of Health, among others, were also considered. Since most municipal data are not aggregated in "metropolitan areas", individual municipality data were used to make the aggregation through a simple mean between the municipalities.

\section{Establishing best and worst scores}

The third step consisted of establishing the best and worst scores for each indicator. Those values are used to rescale the data and will ultimately define the SDG color in the Dashboard, indicating whether the MA has already achieved or it is in a good path toward achieving the goal (green), is in a "caution lane" (yellow), or is expressively far from achievement and where the biggest challenges are (red).

The values for the best (green) and worst (red) score are the upper and lower bounds for each indicator. In most cases, the upper bound was set by the principle of "leaving no one behind" of the Agenda 2030 (e.g., zero poverty or $100 \%$ water supply). For the indicators where no upper bounds could be identified, we used the technical optimum according to other references or the average of the top three values for that indicator (Table 1 - SI). This method of using the average of three top values as upper bound gives us a reference point that is achievable for other MAs in Brazil, yet sufficiently ambitious that only a few of them have attained it (Sachs et al 2016).

For the lower bound, the value was set by the worst value reached among the MAs. These criteria were applied except when: (i) the national average was the worst value, this value became the lower bound; (ii) the worst value was an identified extreme value (outlier ${ }^{1}$ ), the average of the bottom three performers was considered as the worst value. Regarding the last case, extreme values can affect the comparison between data in the same indicator and skew the results of the SDG Dashboard. By replacing extreme values for the average of the bottom three values before setting them as the lower bound, we attenuate the impact of extreme values on the scores and consequently on the final SDG Dashboard.

\footnotetext{
1 Any point of data that lying over 1.5 Interquartile Range (IQR) below the first quartile $\left(Q_{1}\right)$ or above the third quartile $\left(\mathrm{Q}_{3}\right)$ in a dataset. Below: $\left(\mathrm{Q}_{1}\right)-1.5 \mathrm{IQR}$; Above: $\left(\mathrm{Q}_{3}\right)+1.5 \mathrm{IQR}$.
} 
Table 1 Indicators selected according to UNSTAT official set

\begin{tabular}{ll}
\hline Mapping to UNSTATS & $\begin{array}{l}\text { Number of } \\
\text { indicators }\end{array}$ \\
\hline Exact match & 7 \\
Closely aligned & 8 \\
Not in UNSTATS database & 19 \\
Total & 34 \\
\hline
\end{tabular}

\section{Creating dashboards}

For some indicators, the highest numerical value is "best" (e.g., years of schooling), while for others the highest numerical value is "worst" (e.g., illiterate rate). Thus, for comparability purposes, the datasets were rescaled from worst performance (zero) to the ideal value (100) using the upper and low bounds established. An adjusted indicator $^{2}$ was implemented for each MA marking the position of the MA between the worst (0, zero) and ideal case (100). A score of 80 , for example, means that the MA is $80 \%$ of the way from the worst score to the ideal score. For rescaling purposes, any resulting values above 100 were set equal to 100 , and negative values were set equal to 0 (Sachs et al. 2016).

From the rescaled data, we aggregate the indicators for each SDG, averaging across the scores for each SDG's indicators. As recommended by Sachs et al. (2016), we used the arithmetic average with the advantage of being a simple and intuitive method. By this methodology, every indicator has an equal weight inside of the same SDG, and we arrive at 8 SDG scores for each of the 19 MAs.

The SDG scores reflect the performance of the MAs on the SDGs. For turning the SDG Scores into the Dashboard profile, the scores for each MA were divided into three intervals: 0 to $33.33 \%$ (low performance; red color); $33.34 \%$ to $66.66 \%$ (medium performance; yellow color), and $66.67 \%$ to $100 \%$ (high performance; green color). This methodology differs from the one used in the Global SDG Dashboard where absolute thresholds were established to define the colors. While absolute thresholds ensure that a given geography is rated based on its specific need, they fit better for highly diverse geographies (e.g., among countries), and they are best set in consultation with experts-which can be time expensive.

The advantage of using this simple 3-class method is to provide, for similar geographies and in a short time, a quantitative and equidistant dashboard which reflects the distance to be progressed toward SDGs. It is crucial to take into account, however, that when one score borders intervals thresholds (e.g., 33\% or 66\%) this method might classify similar MAs in different colors even having similar profiles.

The SDG Dashboard is a snapshot comparison of all of the 19 Brazilian MAs, showing how close they are to achieving each goal. Besides, the methodology

\footnotetext{
${ }^{2}$ Adjusted indicator: $X^{\prime}=(x-\operatorname{lower}(x)) /(\operatorname{upper}(x)-\operatorname{lower}(x))$.
} 
allows the reader to look into SDG indicators individually for each MA and more accurately identify their weakness and strengths.

\section{Limitation of the data}

The MA's Dashboard considered 34 indicators for 8 SDGs (Table 1). From the official 260 indicators for 17 SDGs (UN 2017), 15 were selected as being the most relevant for the 8 SDGs analyzed for cities in Brazil. Additional 19 indicators were suggested given their relevance to municipal context in the country, ending up with 34 indicators.

One of the biggest obstacles in compiling the indicators was the availability of municipal data. While a wide range of national and state data is available for online access, comparable data on the municipal level are clearly scarcer, especially with regards to climate change, aquatic and terrestrial ecosystems issues (SDGs 13, 14 and 15). Besides, some institutes in charge of providing official data had their website unavailable, or data were out of date, and that is why three consequences had to be considered for this paper.

Firstly, even though we are given preference to most the recent data, two indicators dated from the year 2000 considered significant for the analysis have also been included (Table 1 - SI). Those two indicators belong to the SDG 12 (Responsible Consumption and Production) and illustrate the challenge of gathering updated municipal data especially for environmental indicators. As a result, the Dashboard for the SDG 12 might indicate where a MA was standing in the recent past and not specifically where it currently stands. Likewise, indicators from different recent years were used in the same goal. Although the differences were less than 7 years between them, the snapshot is more harmonized and consistent when the indicators are from the same year. However, it is idealistic to expect municipal data gathered annually for each of the more than 200 SDG indicators in Brazil. This is a limitation most countries face while reporting the national indicators to the $\mathrm{UN}$, presenting the latest data and estimates even when the years differ (UN 2020). Admittedly, the more recent are the indicators for the SDG Dashboard the closer to reality is the MA snapshot.

Secondly, the data gathered were sufficient to build 8 from the initial 12 SDGs proposed (Table 2). The SDGs 2, 13, 14 and 15 were not included in the analysis for not having proper indicators at the municipal level available. Thirdly, only one indicator was used to define the SDG 7 (Affordable and Clean Energy) Dashboard. One snapshot indicator per goal cannot do justice to the complexity of the SDG, and essential aspects will be omitted.

Finally, the three consequences described result from the lack of municipal data, which indicates a demand for investing in statistical capacity at the subnational level to generate reliable data. In fact, the capacity of cities on localizing and implementing the SDGs will depend, more than ever, of precise measurements and monitoring at the subnational level-only possible by accessing social, economic and especially local environmental data (Machado Filho 2016). Despite these gaps and limitations, the SDG Dashboard is helpful to cities in assessing their starting point on the SDGs 
Table 2 SDG Dashboard for Metropolitan Areas in Brazil divided into groups by performance

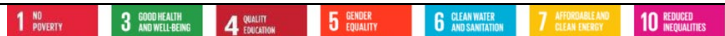

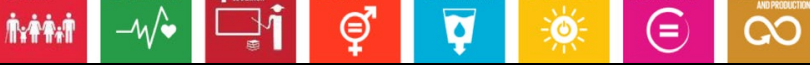

Curitiba
Baixada Santista

1

\section{Campinas}

Vale do Paraíba e Litoral Norte

São Paulo

Distrito Federal and surroundings

Belo Horizonte

2 Goiânia

Grande Vitória

Porto Alegre

Rio de Janeiro

Salvador

Fortaleza

Natal

Belém

3

Maceió

Recife

Grande São Luís

Manaus
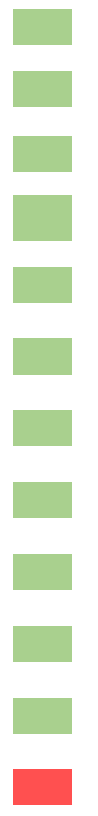

$\sqrt{2}$

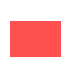

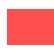
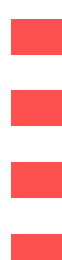
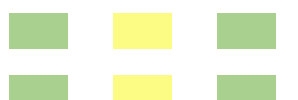

$(2$
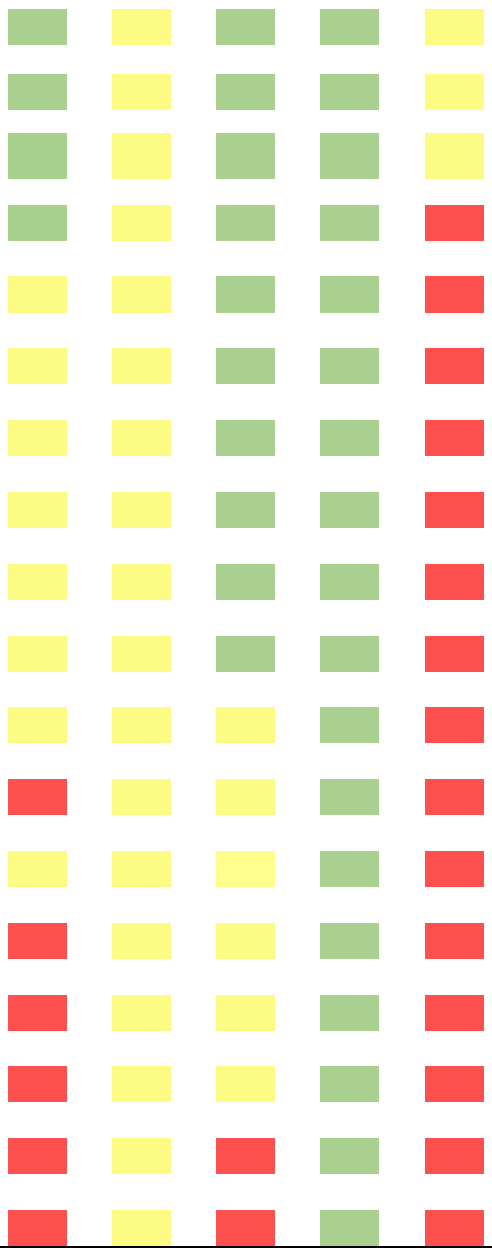
(Kroll 2015) and should be complemented by newly available data and improved analysis in future researches.

\section{Results and discussion}

\section{Progress of SDGs at metropolitan areas}

Among the 8 SDGs analyzed, Curitiba (PR) is the MA which performs best, having five from eight high achievements (green) for the goals, and no low achievement (Table 2). This MA achieved scores above $50 \%$ for 27 of 39 indicators, being on track toward SDG achievement (see Fig. 1-SI). Considered a successful case of sustainable urban planning, the city of Curitiba invests in the involvement of its population on the planning decisions process by a bottom-up approach. The community is engaged in meaningful projects which consequently derive well-being to the inhabitants (Irazábal 2006). In the Dashboard, the MA Curitiba performs better on eradicating poverty (SDG 1), providing water quality (SDG 6), clean and affordable energy (SDG 7). The main challenges rely on indicators related to SDG 3 (health) and 5 (gender equality). When compared to other MAs, MA Curitiba has one of the highest numbers of deaths due to traffic accidents (SDG 3). This alarming number led to initiatives such as the "Dry Law" (Law No. 11.705, dated June 19, 2008), the international "Life in Traffic Project" and Bus Rapid Transit (BRT) System-which also reduced the carbon emission from the transport sector (Wright and Fulton 2005). Although the number is still one of the highest, mortality in traffic in Curitiba has decreased by $45 \%$ between 1996 and 2011 (Barreto et al. 2016). As for gender wage gap (SDG 5), women still receive $26 \%$ less than men in the MA Curitiba, according to our indicator from IBGE (2017).

The following high scores are MAs Baixada Santista, Campinas and Vale do Paraíba, all of them located in the State of São Paulo (SP). In fact, 4 out of top 5 MAs are in São Paulo State, the richest and most populous in Brazil. The MAs presented 4 high (green) and 4 medium (yellow) SDGs achievements, and they differ from the other MAs by having the highest scores on education indicators (SDG 4), such as total years of schooling and National Educational Index (Fig. 1-SI). The high performance in education coincides with the substantial historical and current investments of the State in the sector. Assertive and democratic educational public policies made in past by names such as Paulo Freire could also have contributed to long-term results we see now (O'Cadiz 2018). The State of São Paulo is the largest cluster of research and development in the country and concentrates the highest investment and number of educational institutes (IBGE 2016). The effort is not only on having the most renowned universities but also on primary education. Baixada Santista (SP), for example, has more than $90 \%$ of children at school as a result of recent efforts and investments for maintaining children at school (Ruiz 2015). The high performance in education is mostly what will generate public concern about climate change among the population (Bangay and Blum 2010; Hamilton 2011).

In general, the top 5 presented high achievement on the SDGs regarding poverty, education, water quality and energy access, but they are still half of the way through 
providing good health, gender equality and, in particular, to reduce inequalities. For instance, the MA São Paulo, one of the major urban centers of Latin America, performed $20 \%$ worst in the SDG 10 (reduce inequalities) when compared to the other 3 MAs in the same State. Not surprisingly, the SDG 10 is a challenge not only for the top 5 MAs, but shared by all the MAs. Although poorer MAs from North and Northeast region are in general more unequal than the richer MAs in South and Southeast, the SDG 10 is the SDG that all MAs in Brazil are currently further to achieve.

The results are in line with the historical widening gap between rich and poor throughout the country. Latin America has been struggling to reduce inequality mostly since the $70 \mathrm{~s}$, presenting one of the highest degrees of inequality in absolute terms (Londoño and Székely 2000). In Brazil, indicators have shown that the country has had some success in reducing poverty and inequality over the last two decades, but still has much more to do to ensure its GDP growth translates into a broadbased improvement in living standards. According to the World Economic Forum Report in Inclusive Growth and Development, one way of translating the increased GDP in reducing inequalities is reforming Brazil's education system (Samans et al. 2015). The hypothesis is that a high-quality public education system can minimize the extent to which inequality of wealth becomes inequality of opportunity in the next generation. As evidence for confirming the hypothesis, our results have shown that the MAs with high performance in education are less unequal (Table 2).

One exception observed is the MA Distrito Federal and surroundings, where good performance on education does not match low inequality, presenting the highest inequality among the MAs. This MA where the national capital is located has a particular characteristic: the concentration of public sector jobs. Over the last ten years, income inequality has increased in this MA especially as a result of raising on the public sector salaries not followed by an increase in the remaining sectors' salaries (Mader 2012).

High inequality is also found in gender comparisons (SDG 5) in all 19 MAs analyzed. As mentioned for the MA Curitiba, our results indicate that although women have more years of schooling, they still receive 18 to $27 \%$ less than men among the MAs (Fig. 1 - SI). The gender inequality is by far higher in MA Manaus (AM), located in the isolated Amazon region. Among the MAs, Manaus presented the lowest female labor participation and highest teenage birth rates and sexual violence incidence. The feminicide and violence against women have a long history in Brazil which ranks the fifth country with the highest rate of homicides per 100,000 women (Waiselfisz 2015). However, this situation is intensified in remote areas and where the highly patriarchal structure contributes to the silencing of victims and perpetuation of gender violence (Velloso 2017). In 2010, Manaus had the third-highest rate of gender violence in Brazil, with 11.5 women killed per 100,000 people (Brasil 


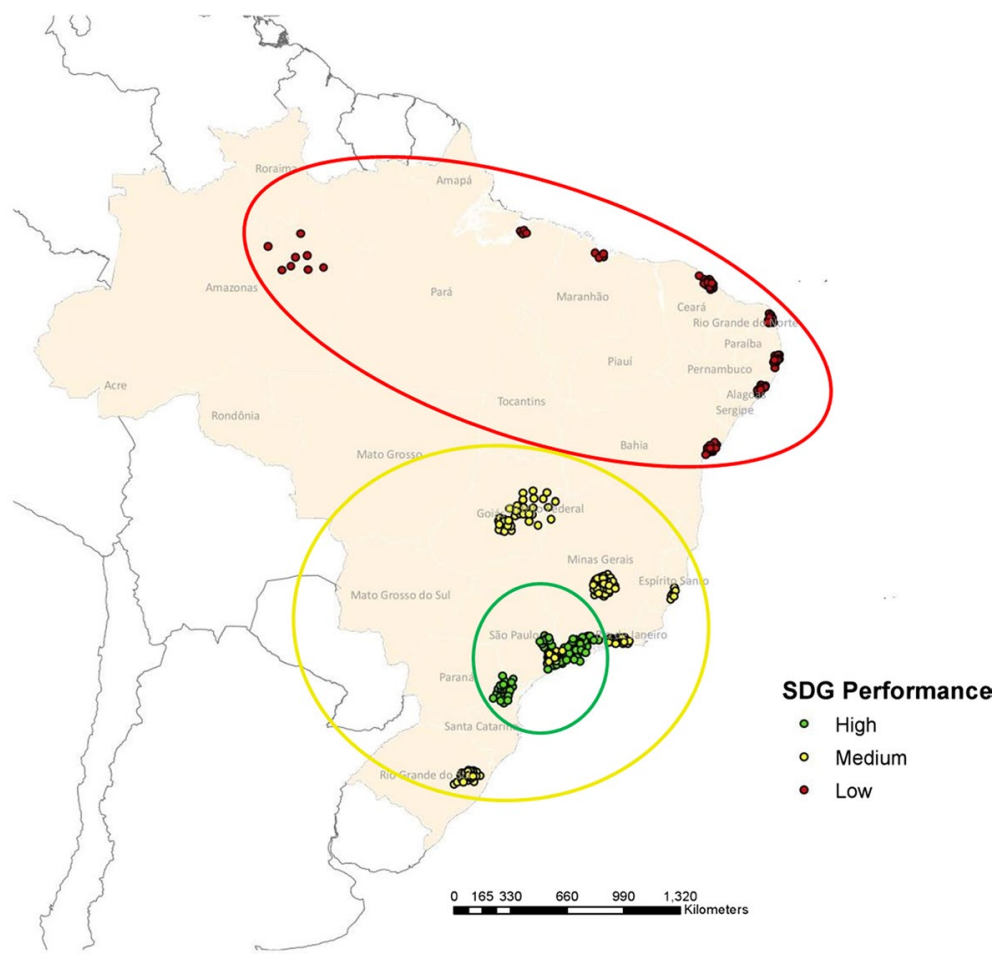

Fig. 3 Map of MAs according to the SDG Dashboard performance. Green: high performance; Yellow: medium performance; Red: low performance. Source Author's elaboration

2015). On the other hand, the increasing awareness of Manaus' current situation has encouraged innovative initiatives in deterring violence against women led by the State itself, such as training the police in the enforcement of the Maria da Penha $\mathrm{Law}^{3}$ and providing services to women through the use of mobile units like boats and buses (Ceratti 2015).

MA Manaus is on the bottom of the dashboard along with MA Grande São Luís (MA), presenting high levels of poverty, low quality of education, and poor access to water, sanitation and waste collection when compared to the other MAs or the ideal scenario for the SDG. The only SDG they had high performance was on the affordable and clean energy SDG (7) - equally achieved by all other MAs. Even though Manaus is located in the center of the Amazon region and further from other large urban centers, its municipalities had high achievement in clean energy mainly on behalf of national programs for providing electricity for rural and urban

\footnotetext{
${ }^{3}$ Law 11.340/2006 - It creates mechanisms to restrain domestic and family violence against women, under the terms of $\S 8$ of art. 226 of the Brazilian Federal Constitution, in line with the Convention on the Elimination of All Forms of Discrimination against Women, and with the Inter-American Convention to Prevent, Punish and Eradicate Violence Against Women.
} 
areas in Brazil (Drummond 2016). Because this SDG was measured through only one indicator (Table 1 - SI), further research is needed to measure the real progress of MAs on achieving clean energy and reducing their emissions, especially for the MAs located in the Amazon. Along with agricultural expansion, the urban spread and road construction in the Amazon basin promote tropical deforestation by landuse changes, which is by far the country's largest source of emissions (WRI 2019). The city of Manaus has doubled its size in the last 30 years, not only emitting more carbon but also changing the local atmospheric circulation and its microclimate features (Souza et al 2016).

\section{North-south gap on the implementation of SDGs}

In summary, the Dashboard divides the MAs into a clear north-south distinction, showing that this methodology is sensitive to regional disparities. If we group the MAs by color of performance, the top two-thirds are located in the Southern part of the country (Southeast, Midwest and South Regions-group 1 and 2), while the bottom one-third in Northern (North and Northeast_-group 3) (Table 2, Fig. 3). The regional division corresponds relatively to the level of achievement for the SDG 1 (Poverty), SDG 4 (education) and SDG 6 (Water). The historical income inequality between Brazilian regions might play a role on this result: Southeast Region alone is responsible for approximately $60 \%$ of the national GDP, while Northern and Northeast together represent less than 20\% (IBGE 2014).

Two development topics the Brazilian MAs are performing well are reducing poverty (SDG 1) and providing water and sanitation (SDG 6). For the SDG 1, the top two-thirds showed high achievement on having less poverty and providing social benefits to the poorest. Despite the persistent high inequality, Brazil has had relevant achievements on social protection over the last years by improving its adequacy of social assistance and social insurance programs (Samans et al. 2015). For instance, the MA Campinas, who scored highest for the SDG 1, has been one of the leading partners of the national government to provide public education, daycare, food and housing for the poorest through cash transfer programs (G1 Campinas 2015).

The SDG Dashboard also shows the top two-thirds of the MAs presenting high achievement on providing water and sanitation (SDG 6). Although most of the municipalities are on the path to achieve the SDG 6, the country itself will not achieve the water supply and wastewater collection universalization in 2030 unless cities start to heavily invest on stepping up the speed of providing those services ((TrataBrasil 2013) — which could cost up to US\$ 50 billion annually (Andersson et al. 2017). From its more than 200 million inhabitants, less than half (43\%) of the Brazilian population has sewage collection and treatment (ANA 2017). The best performer on the SDG 6, MA Belo Horizonte, is following this path. Belo Horizonte has $100 \%$ of wastewater collection and is currently investing in universalizing the wastewater treatment (IDB 2013).

Finally, the SDG Dashboard expresses similar performance among the MAs for three SDGs: SDG 3 (health and well-being), SDG 5 (Gender equality) and SDG 12 (responsible consumption and production). In general, all of them are in a "caution 
lane" for the three SDGs, but they differ themselves in performance at indicators level (Fig. 1 - SI). Using the example of the SDG 3, if on the one hand all MAs performed poorly in "maternal death rate", on the other hand most of them are well on the way to achieving the target for "AIDS diagnosis", echoing Brazil's internationally recognized performance on providing greater access to HIV care (WHO 2018). The same for SDG 5, where despite data have indicated women having same or higher amount of schooling years than men, the former are not as much part of the labor market as the latter for most of the MAs. For the SDG 12, the fact that most of the MAs are on track for achieving $100 \%$ of waste collection does not imply in taking one step further implementing recycling plants. Thus, looking to indicators individually enable the SDG Dashboard to be used as basis for enhancing local policies toward the implementation of the SDGs.

\section{Conclusion}

Our results have shown that under the same national-level conditions, there is a difference between the SDG performances among MAs in Brazil, which means some perform better than others toward achieving the SDGs. According to the performance obtained, the SDG Dashboard can be divided regionally into north-south distinction: the top two-thirds located in Southern region, while the bottom one-third in Northern. Those results might be due not exclusively to economic aspects, but also by each MA's own history, culture, geography and quality of its institutions (Hofstede 2003). Also, the differences between the MAs ended up in different solutions that each city has used to overcome challenges. In this case, peer-learning actions would accelerate the practical knowledge to improve their performance toward the SDGs. For immediate policy recommendation, the priority should be given to municipal strategies for improving education, since it would also tackle other SDGs, helping to decrease inequality and reduce poverty.

Furthermore, the results have demonstrated that the SDGs are connected and have influence on each other, and therefore should not be seen as single goals. The interrelations between SDGs should be explored further in future research addressing challenges for implementing the SDGs at the local level. Also as a next step, the reactions of city governments and related actors to this visual SDG Dashboard methodology could be analyzed using surveys and interviews, and investigate their level of understanding of the provided information and their willingness of implementing the suggestions.

In conclusion, the SDG Dashboard provided a MA profile for 8 SDGs, highlighting weaknesses and strengths of MAs, being a tool for improving management and for bringing local subnational government to the forefront of international politics. In addition, this paper serves as a basis for expanding the SDG Dashboard to all 17 SDGs and for building a local SDG Index for Brazil in the future. As we contend that the urban agglomeration will become the primary carrier for the socioeconomic development of Brazil in the foreseeable future, we strongly encourage continuous research and SDG monitoring with regular inclusion of new local indicators that support the calculation of progress and trend analysis of the SDGs at MAs. 
Supplementary Information The online version contains supplementary material available at https://doi. org/10.1007/s43545-021-00131-8.

Acknowledgements Besides our funding bodies, we would like to thank David Durand-Delacre for his academic support and insightful comments while part of the SDG Index team at Sustainable Development Solutions Network (SDSN).

Funding Open Access funding enabled and organized by Projekt DEAL. This paper received financial support from the Federal Ministry of the Environment, Nature Conservation and Nuclear Safety (BMU) while the main author was participant of the CIPSEM postgraduate course program.

Data availability All data generated or analyzed during this study are included in the references of this published article [and its supplementary information files].

\section{Declarations}

Conflict of interest The authors declare that they have no conflict of interest.

Open Access This article is licensed under a Creative Commons Attribution 4.0 International License, which permits use, sharing, adaptation, distribution and reproduction in any medium or format, as long as you give appropriate credit to the original author(s) and the source, provide a link to the Creative Commons licence, and indicate if changes were made. The images or other third party material in this article are included in the article's Creative Commons licence, unless indicated otherwise in a credit line to the material. If material is not included in the article's Creative Commons licence and your intended use is not permitted by statutory regulation or exceeds the permitted use, you will need to obtain permission directly from the copyright holder. To view a copy of this licence, visit http://creativecommons.org/licen ses/by/4.0/.

\section{References}

ANA - Brazilian National Water Agency (2017) Atlas Esgotos: Despoluição de Bacias Hidrográficas. In: Agência Nacional de Águas do Brasil. Brasília, Brasil. http://atlasesgotos.ana.gov.br/. Accessed 14 Aug 2019

Andersson K, Otoo M, Nolasco M (2017) Innovative sanitation approaches could address multiple development challenges. Water Sci Technol 77(4):855-858. https://doi.org/10.2166/wst.2017.600

Arcadis (2018) Citizen centric cities: sustainable cities index 2018 Europe

Atlas Brasil (2013) Atlas do Desenvolvimento Humano do Brasil. http://www.atlasbrasil.org.br/2013/pt/ perfil/. Accessed 12 Apr 2017

Aust HP, du Plessis A (2018) The globalisation of urban governance. Routledge, London

Bangay C, Blum N (2010) Education responses to climate change and quality: two parts of the same agenda? Int J Educ Dev 30:359-368

Brasil (1988) Federal Constitution of Brazil. 3rd Paragraph, Art. 25

Brasil (2015) Ministério da Saúde. Departamento de Informática do Sistema Único de Saúde (DATASUS) [online]. Brasília. http://tabnet.datasus.gov.br/cgi/deftohtm.exe?idb2011/c09.def

Brazilian Federal Law 11.445/2007

Brazilian Federal Law 11.705/2008

CBD, Convention on Biological Diversity (2019) City Biodiversity Index (or Singapore Index). https:// www.cbd.int/subnational/partners-and-initiatives/city-biodiversity-index

Ceratti MK (2015) Brazil: five things you didn't know about the state of Amazonas. World Bank. http://www.worldbank.org/en/news/feature/2015/03/02/five-things-you-didnt-know-about-amazo nas-amazon-brazil

Croese S, Green C, Morgan G (2020) Localizing the sustainable development goals through the lens of urban resilience: lessons and learnings from 100 Resilient Cities and Cape Town. Sustainability $12: 550$ 
Cutter A, Osborn D, Romano D, Ullah F (2015) Sustainable development goals and integration: achieving a better balance between the economic, social and environmental dimensions. Stakeholder Forum, Germany

da Barreto M, S., Teston, E. F., Latorre, M. R. D. O., Mathias, T. A. F., \& Marcon, S. S. (2016) Traffic *****accident and homicide mortality in Curitiba, Paraná, Brazil, 1996-2011. Epidemiologia e Serviços de Saúde 25(1):95-104

Doll C (2019) Cities should be at the heart of the SDGs. In: United Nations University. https://unu.edu/ publications/articles/cities-heart-of-sdgs.html

Drummond C (2016) Entenda como funciona o Luz para Todos. In: Carta Capital. https://www.cartacapit al.com.br/especiais/infraestrutura/entenda-como-funciona-o-luz-para-todos

Duranton G, Puga D (2004) Micro-foundations of urban agglomeration economies. In: Henderson V, Thisse J-F (eds) Handbook of regional and urban economics, vol 4. North-Holland, Amsterdam, pp 2119-2171

Fang C, Yu D (2017) Urban agglomeration: an evolving concept of an emerging phenomenon. Landsc Urban Plan 162:126-136

G1 Campinas (2015) Campinas tem 40 mil pessoas na linha da pobreza extrema, afirma Prefeitura. http:// g1.globo.com/sp/campinas-regiao/noticia/2015/06/campinas-tem-40-mil-pessoas-na-linha-da-pobre za-extrema-afirma-prefeitura.html

Gottmann J (1957) Megalopolis, or the urbanization of the North-eastern seaboard. Econ Geogr 33(7):189-200

GTLRG - Global Taskforce of Local and Regional Governments - UN-Habitat and UNDP (2016) Roadmap for localizing the SDGs: implementation and monitoring at subnational level. https://www. uclg.org/sites/default/files/roadmap_for_localizing_the_sdgs_0.pdf

Hamilton LC (2011) Education, politics and opinions about climate change evidence for interaction effects. Clim Change 104:231. https://doi.org/10.1007/s10584-010-9957-8

Hofstede G (2003) Culture's consequences: comparing values, behaviors, institutions and organizations across nations. Sage publications

IAEG-SDGs: inter-agency expert group on SDG indicators (2016) Provisional proposed tiers for global SDG indicators as of March 24, 2016. Inter-Agency Expert Group on SDG Indicators, New York

IBGE - Instituto Brasileiro de Geografia e Estatística (2016) Estado: São Paulo. http://www.ibge.gov.br/ estadosat/temas.php?sigla $=$ sp\&tema $=$ educacao 2015

IBGE - Instituto Brasileiro de Geografia e Estatística (2017) Estimativas populacionais para os municípios e para as Unidades da Federação brasileiros em 01.07.2016. https://ww2.ibge.gov.br/home/estat istica/populacao/estimativa2016/default.shtm

ICSU - International Council for Science (2017) A guide to "SDG" interactions: from science to implementation. France, Paris

IDB - Inter-American Development Bank (2013) Mais 42 mil pessoas em Belo Horizonte vão ter acesso à água mais limpa e esgoto tratado. http://www.iadb.org/pt/noticias/comunicados-de-imprensa/ 2013-12-18/melhor-qualidade-da-agua-em-belo-horizonte, 10720.html

Irazábal C (2006) Localizing urban design traditions: gated and edge cities in Curitiba. J Urban Des 11(1):73-96. https://doi.org/10.1080/13574800500297736

Jahan S (2016) Human development report 2016: human development for everyone. UNDP, New York

Kroll C (2015) Sustainable development goals: are the rich countries ready? Bertelsmann Foundation, Gütersloh

Liu J, Hull V, Godfray HCJ et al (2018) Nexus approaches to global sustainable development. Nat Sustain 1:466-476. https://doi.org/10.1038/s41893-018-0135-8

Londoño JL, Székely M (2000) Persistent poverty and excess inequality: Latin America, 1970-1995. J Appl Econ 3(1):93-134. https://doi.org/10.1080/15140326.2000.12040547

Machado Filho H (2016) Roteiro para a Localização dos Objetivos de Desenvolvimento Sustentável: Implementação e Acompanhamento no nível subnacional. Organização das Nações Unidas, Brasil, p 82

Mader H (2012) Abismo social que separa ricos e pobres aumenta em Brasília. In: Correio Braziliense. http://www.correiobraziliense.com.br/app/noticia/cidades/2012/01/20/interna_cidadesdf,286983/ abismo-social-que-separa-ricos-e-pobres-aumenta-em-brasilia.shtml

O'Cadiz P (2018) Education and democracy: Paulo Freire, social movements, and educational reform in São Paulo. Routledge, London

OECD - Organization for Economic Cooperation and Development (2008) Handbook on constructing composite indicators: methodology and user guide. France, Paris

\section{SN Social Sciences}

A SPRINGER NATURE journal 
Pahl-Wostl C (2017) Governance of the water-energy-food security nexus: a multi-level coordination challenge. Environ Sci Policy. https://doi.org/10.1016/j.envsci.2017.07.017

Prakash M, Teksoz K, Espey J, Sachs J, Shank M (2017) Achieving a Sustainable Urban America-the U.S. Cities Sustainable Development Goals Index. New York: SDSN Working Paper

Portnov BA, Schwartz M (2009) Urban clusters as growth foci. J Reg Sci 49(2):287-310

RIDEsab (2017) O que são RIDEs?. http://ridesab.com.br/o-que-sao-rides/

Ruiz L (2015) Com melhora em educação, Campinas e Santos avançam em desenvolvimento humano. In: UOL Notícias. https://noticias.uol.com.br/ultimas-noticias/agencia-estado/2015/07/01/melhora-emeducacao-faz-campinas-e-santos-aumentarem-idhm.htm

Sachs J, Schmidt-Traub G, Kroll C, Durand-Delacre D, Teksoz K (2016) SDG Index and dashboardsglobal report. New York: Bertelsmann Stiftung and Sustainable Development Solutions Network (SDSN)

Samans R, Blanke J, Corrigan G, Drzeniek M (2015) The inclusive growth and development report. World Bank, Washington, DC

Schmidt-Traub G, Kroll C, Teksoz K, Durand-Delacre D, Sachs JD (2017) National baselines for the sustainable development goals assessed in the SDG index and dashboards. Nat Geosci 10:547-555

Slack E (2011) Financing large cities and metropolitan areas. IMFG papers on municipal finance and governance, n.3. Published by: University of Toronto

Souza DO, Alvalá RCS, Nascimento MG (2016) Urbanization effects on the microclimate of Manaus: a modeling study. Atmos Res 167:237-248

Waiselfisz JJ (2015) Mapa da Violência 2015 - Homicídios de mulheres no Brasil

WHO - World Health Organization (2018). Brazil highlights treatment for all people with HIV. Available at: https://www.who.int/hiv/mediacentre/news/brazil-hiv-treatment-all-plhiv/en/

WRI - World Resources Institute (2019) Climate analysis indicators tool: WRI's climate data explorer. http://cait.wri.org/historic

Wright L, Fulton L (2005) Climate change mitigation and transport in developing nations. Transp Rev 25(6):691-717. https://doi.org/10.1080/01441640500360951

TrataBrasil (2013). Baixo avanço do saneamento básico nas maiores cidades brasileiras compromete universalização nos próximos 20 anos. http://www.tratabrasil.org.br/datafiles/estudos/ranking/releaseranking-2014.pdf

UN-United Nations (2015) Transforming our world: the 2030 agenda for sustainable development

UN-United Nations (2017) Work of the statistical commission pertaining to the 2030 agenda for sustainable development. A/RES/71/313. https://undocs.org/A/RES/71/313

UN-United Nations (2019) Independent group of scientists appointed by the secretary-general, global sustainable development report 2019: the future is now-science for achieving sustainable development. 24797GSDR_report_2019.pdf (un.org)

UN_United Nations (2020) Sustainable development goals report. https://www.un.org/sustainabledeve lopment/progress-report/

UN DESA-United Nations, Department of Economic and Social Affairs, Population Division (2014) World urbanization prospects: the 2014 revision, highlights (ST/ESA/SER.A/352)

Velloso C (2017) The current state of gender in Brazil. Wilson Center. https://www.wilsoncenter.org/ blog-post/the-current-state-gender-brazil

Zeug W, Bezama A, Moesenfechtel U, Jähkel A, Thrän D (2019) Stakeholders' interests and perceptions of bioeconomy monitoring using a sustainable development goal framework. Sustainability 11:1511 